\title{
Improvement of biosurfactant production by Wickerhamomyces anomalus CCMA 0358 and its potential application in bioremediation
}

\author{
Karla S. Teixeira Souza ${ }^{a}$, Eduardo J. Gudiña ${ }^{\mathrm{b}, *}$, Rosane F. Schwan ${ }^{\mathrm{a}}$, Lígia R. Rodrigues ${ }^{\mathrm{b}}$, \\ Disney R. Dias ${ }^{c}$, José A. Teixeira ${ }^{b}$ \\ a Department of Biology, Federal University of Lavras (UFLA), Campus Universitário, 37.200-000 Lavras, MG, Brazil \\ ${ }^{\mathrm{b}}$ CEB - Centre of Biological Engineering, University of Minho, 4710-057 Braga, Portugal \\ c Department of Food Science, Federal University of Lavras (UFLA), Campus Universitário, 37.200-000 Lavras, MG, Brazil
}

\section{H I G H L I G H T S}

- Wickerhamomyces anomalus CCMA 0358 produced a promising biosurfactant.

- Biosurfactant production was optimized through response surface methodology.

- The surface tension was reduced in $24 \mathrm{~h}$ from $49 \mathrm{mN} / \mathrm{m}$ up to $29 \mathrm{mN} / \mathrm{m}$ in bioreactor

- The biosurfactant was stable at extreme conditions of salinity and temperature.

- The biosurfactant facilitated the recovery of $20 \%$ of oil from contaminated sand.

\section{A R T I C L E I N F O}

\section{Article history:}

Received 27 July 2017

Received in revised form

12 November 2017

Accepted 7 December 2017

Available online 8 December 2017

\section{Keywords:}

Wickerhamomyces anomalus

Biosurfactant

Bioreactor

Response surface methodology

Bioremediation

\begin{abstract}
A B S T R A C T
In this work, biosurfactant production by Wickerhamomyces anomalus CCMA 0358 was increased through the development of an optimized culture medium using response surface methodology. The optimized culture medium contained yeast extract $(4.64 \mathrm{~g} / \mathrm{L})$, ammonium sulfate $(4.22 \mathrm{~g} / \mathrm{L})$, glucose $(1.39 \mathrm{~g} / \mathrm{L})$ and olive oil $(10 \mathrm{~g} / \mathrm{L})$. Biosurfactant production using this medium was validated both in flasks and bioreactor, and the surface tension was reduced from $49.0 \mathrm{mN} / \mathrm{m}$ up to $31.4 \mathrm{mN} / \mathrm{m}$ and $29.3 \mathrm{mN} / \mathrm{m}$, respectively. In both cases, the highest biosurfactant production was achieved after $24 \mathrm{~h}$ of growth. W. anomalus CCMA 0358 demonstrated to be a fast biosurfactant producer $(24 \mathrm{~h}$ ) as compared to other yeast strains previously reported $(144-240 \mathrm{~h})$. The produced biosurfactant remained stable at high temperature $\left(121^{\circ} \mathrm{C}\right), \mathrm{NaCl}$ concentrations as high as $300 \mathrm{~g} / \mathrm{L}$, and $\mathrm{pH}$ values between 6 and 12 . The crude biosurfactant allowed the recovery of $20 \%$ of crude oil from contaminated sand, being a promising candidate for application in bioremediation or in the petroleum industry.
\end{abstract}

(c) 2017 Elsevier B.V. All rights reserved.

\section{Introduction}

Surface-active compounds (surfactants) exhibit a wide variety of applications and are present in nearly every product and aspect of our daily life. They are included as active ingredients in the formulation of detergents, cleaning and personal care products and cosmetics, and are also used in bioremediation, as well as in agriculture, food, paper, textile and petroleum industries, among others [1-7]. Due to their structure, surfactants reduce the surface and

\footnotetext{
* Corresponding author at: CEB - Centre of Biological Engineering, University of Minho, Campus de Gualtar, 4710-057 Braga, Portugal.

E-mail addresses: egudina@deb.uminho.pt, b4250@deb.uminho.pt (E.J. Gudiña).
}

interfacial tensions, which confers them properties such as detergency, emulsifying activity, foaming, and ability to solubilize and disperse hydrophobic compounds in aqueous phases $[1,8,9]$. The current worldwide production of surfactants is estimated to be 15 million tons per year [3]. Most of the traditional chemical surfactants commonly used are obtained from petrochemical resources, and exhibit high toxicity and low biodegradability [9,10]. Given the increasing concern regarding the environmental hazard of synthetic surfactants, and in order to address the growing demand for eco-friendly alternatives, research focusing on the production of bio-based surfactants has increased in the past few years [11]. The market for these "green" alternatives to the traditional chemical surfactants is expected to increase up to USD 2800 million by 2023 , with a worldwide production around 462 kilo tons per year [12]. 
Among the bio-based surfactants, biosurfactants, a heterogeneous group of surface-active compounds synthesized by different microorganisms, have emerged as promising alternatives to the synthetic surfactants. In the past 10 years, biosurfactants have received pronounced attention owing to their excellent interfacial activities, low toxicity, high biodegradability, and stability under extreme conditions of temperature, $\mathrm{pH}$ and salinity $[4,8,11,13]$. As a result of these properties, biosurfactants could replace chemical surfactants in many industrial applications [14-18]. However, their large-scale industrial production and commercialization are still limited by the relatively low efficiency of their production and recovery processes, as well as the high price of the culture media used for their synthesis, which results in high production costs. Extensive efforts have been made to produce biosurfactants at a competitive cost through the use of agro-industrial wastes and byproducts as substrates, and the development of effective recovery processes [3,9,19-26]. Furthermore, the application of statistical experimental designs such as response surface methodology (RSM) has been successfully used to optimize the composition of the culture medium and the culture conditions to maximize biosurfactant production by different microorganisms [23-25].

In this work, the composition of the culture medium was optimized through RSM to increase the biosurfactant production by Wickerhamomyces anomalus CCMA 0358. The results obtained were validated in shaken flasks and bioreactor. The stability of the biosurfactant produced by this yeast at different environmental conditions, as well as its potential applicability in bioremediation was also studied.

\section{Experimental}

\subsection{Strain and culture conditions}

The yeast strain $W$. anomalus CCMA 0358 (isolated from coffee processing by-products) was obtained from the Culture Collection of Agricultural Microbiology, CCMA (Department of Biology, Federal University of Lavras, Brazil). This isolate was identified as a promising biosurfactant producer in our previous work [27]. The yeast was grown in YEPG medium ( $10 \mathrm{~g} / \mathrm{L}$ yeast extract; $20 \mathrm{~g} / \mathrm{L}$ peptone; $20 \mathrm{~g} / \mathrm{L}$ glucose; $\mathrm{pH} 6.5$ ) at $28^{\circ} \mathrm{C}$ and $200 \mathrm{rpm}$.

\subsection{Biosurfactant production}

The culture medium used for the production of biosurfactant by $W$. anomalus CCMA 0358 consisted of: $4 \mathrm{~g} / \mathrm{L}$ yeast extract; $2 \mathrm{~g} / \mathrm{L}$ glucose; $4 \mathrm{~g} / \mathrm{L}$ ammonium sulfate; and $20 \mathrm{~g} / \mathrm{L}$ olive oil [27]. The experiments were performed in flasks ( $500 \mathrm{~mL}$ capacity) containing $200 \mathrm{~mL}$ of culture medium. Each flask was inoculated with a pre-culture of $W$. anomalus CCMA 0358 (grown overnight in YEPG medium at $28^{\circ} \mathrm{C}$ and $200 \mathrm{rpm}$ ) to attain an initial cell concentration of $10^{7}$ cells $/ \mathrm{mL}$. Subsequently, the flasks were incubated at $28^{\circ} \mathrm{C}$ and $200 \mathrm{rpm}$ for $24 \mathrm{~h}$. Samples $(4 \mathrm{~mL})$ were taken along the fermentation to evaluate growth and biosurfactant production. Cell growth was determined according to the number of cells counted using a Neubauer improved cell counter (Marienfeld GmbH, Germany). Afterwards, the samples were centrifuged $(2700 \times g, 15 \mathrm{~min})$ and the cell-free supernatants were used to assess biosurfactant production through surface tension measurement, as described below.

\subsection{Surface tension measurement}

The surface tension of the cell-free supernatants was measured according to the Ring method as described elsewhere [27]. A KRÜSS K6 Tensiometer (KRÜSS GmbH, Germany) equipped with a $1.9 \mathrm{~cm}$
Table 1

Central composite design factors and corresponding variation ranges according to the experimental levels.

\begin{tabular}{llllll}
\hline \multicolumn{7}{l}{ Levels } & & & \\
\hline Factor & -1.68 & -1 & 0 & +1 & +1.68 \\
\hline & \multicolumn{7}{l}{ Concentration $(\mathrm{g} / \mathrm{L})$} & & & \\
\hline Yeast Extract $\left(X_{1}\right)$ & 0.60 & 2.0 & 4.0 & 6.0 & 7.4 \\
Ammonium Sulfate $\left(X_{2}\right)$ & 0.60 & 2.0 & 4.0 & 6.0 & 7.4 \\
Glucose $\left(X_{3}\right)$ & 0.32 & 1.0 & 2.0 & 3.0 & 3.68 \\
\hline
\end{tabular}

Table 2

Matrix of the central composite design showing the concentration of the different factors for the experimental design and the results of the experimental runs (predicted and observed).

\begin{tabular}{lllllll}
\hline \multirow{2}{*}{ Experiment } & \multicolumn{2}{l}{ Concentration $(\mathrm{g} / \mathrm{L})$} & & \multicolumn{2}{l}{$\mathrm{ST}(\mathrm{mN} / \mathrm{m})$} & \\
\cline { 2 - 3 } \cline { 6 - 7 } & $X_{1}$ & $X_{2}$ & $X_{3}$ & & Predicted & Observed \\
\hline 1 & 2 & 2 & 1 & & 34.4 & 33.2 \\
2 & 6 & 2 & 1 & & 31.8 & 30.9 \\
3 & 2 & 6 & 1 & & 34.2 & 33.5 \\
4 & 6 & 6 & 1 & & 31.9 & 30.9 \\
5 & 2 & 2 & 3 & & 34.3 & 34.3 \\
6 & 6 & 2 & 3 & & 32.1 & 31.9 \\
7 & 2 & 6 & 3 & & 35.3 & 35.3 \\
8 & 6 & 6 & 3 & & 33.3 & 33.5 \\
9 & 0.6 & 4 & 2 & & 38.8 & 39.5 \\
10 & 7.4 & 4 & 2 & & 35.0 & 35.7 \\
11 & 4 & 0.6 & 2 & & 30.0 & 30.9 \\
12 & 4 & 7.4 & 2 & & 30.9 & 31.4 \\
13 & 4 & 4 & 0.32 & 32.2 & 34.0 \\
14 & 4 & 4 & 3.68 & 33.3 & 32.9 \\
15 & 4 & 4 & 2 & 31.9 & 32.0 \\
16 & 4 & 4 & 2 & 31.9 & 31.8 \\
17 & 4 & 4 & 2 & 31.9 & 31.6 \\
\hline
\end{tabular}

De Noüy platinum ring was used. All the measurements were performed in triplicate at room temperature $\left(25^{\circ} \mathrm{C}\right)$.

\subsection{Culture medium optimization through response surface methodology (RSM)}

The composition of the culture medium described above was optimized in order to maximize biosurfactant production by $W$. anomalus CCMA 0358. The concentration of three medium components and the effect of the interactions between them on biosurfactant production were analyzed and optimized by RSM using a central composite design (CCD). The medium components (independent factors) selected to perform the optimization process were yeast extract $\left(X_{1}\right)$, ammonium sulfate $\left(X_{2}\right)$ and glucose $\left(X_{3}\right)$. Each factor was studied at five coded levels $(-1.68,-1,0,+1,+1.68)$, as shown in Table 1 . Statistica 8.0 software was used to generate a set of 17 experiments, which included 3 replicates at the central point (Table 2).

The experiments were performed in flasks ( $500 \mathrm{~mL}$ capacity) containing $200 \mathrm{~mL}$ of the different culture media (prepared according to the CCD (Table 2)); all the media were supplemented with $20 \mathrm{~g} / \mathrm{L}$ of olive oil. The flasks were inoculated and incubated at the same conditions described above. Cell growth and biosurfactant production were evaluated as previously described. The surface tension values obtained for each experimental run were taken as the response variable, and the biosurfactant production was assessed as the surface tension reduction. All experiments were performed in triplicate.

The experimental results of RSM were fitted via the response surface regression procedure, using the following second-order 
polynomial equation to define the predicted responses in terms of the independent factors:

$Y=\beta_{0}+\sum_{i} \beta_{i} X_{i}+\sum_{i i} \beta_{i i} X_{i}^{2}+\sum_{i j} \beta_{i j} X_{i} X_{j}$

where $Y$ is the predicted response value; $\beta_{0}$ is the intercept term; $\beta_{i}$ are the linear coefficients; $\beta_{i i}$ are the quadratic coefficients; $\beta_{i j}$ are the interaction coefficients; and $X_{i}-X_{j}$ are the independent factors.

Statistica 8.0 software was used for the analysis of the experimental designs and subsequent regression analysis of the experimental data obtained. The coefficient of determination $\left(R^{2}\right)$ was used as a parameter of quality of the polynomial model equation. The statistical significance of the model equation and the model terms was evaluated through the $F$-test, whereas the $t$-test was used to evaluate the significance of the regression coefficients. The fitted polynomial equation was then expressed in the form of response surfaces to illustrate the individual and combinatorial effect of the factors evaluated on the responses. The point optimization method was used to optimize the level of each factor towards a maximum response (i.e. to predict the optimum concentration of each medium component for maximum surface tension reduction). Subsequently, the model was validated by performing the experimental runs suggested during the statistical optimization of the model (i.e. the combination of different optimized factors which yielded the maximum response).

After optimizing the selected culture medium components (yeast extract, ammonium sulfate and glucose), the effect of different olive oil concentrations $(0,10,20,30,40$ and $50 \mathrm{~g} / \mathrm{L})$ on the biosurfactant production was studied. The culture conditions used were the same as described above and the experiments were conducted in triplicate.

\subsection{Biosurfactant production in bioreactor}

A 5-L capacity bioreactor (BIOSTAT ${ }^{\circledR}$ A Fermentor, B. Braun Biotech International $\mathrm{GmbH}$, Germany), equipped with agitation, temperature, $\mathrm{pH}$ and dissolved oxygen concentration online measurement and control was used. The experiments were performed at $28^{\circ} \mathrm{C}$, using $2 \mathrm{~L}$ of the previously optimized culture medium, with air injected in the bottom of the bioreactor at a constant flow rate of $1 \mathrm{~L} / \mathrm{min}$ and without $\mathrm{pH}$ control. The fermentations were conducted as batch cultivations. The bioreactor was inoculated with a pre-culture of $W$. anomalus CCMA 0358 (grown overnight in YEPG medium at $28^{\circ} \mathrm{C}$ and $200 \mathrm{rpm}$ ) to attain an initial cell concentration of $10^{7}$ cells $/ \mathrm{mL}$. The effect of different agitation rates (250, $300,350,400$ and $500 \mathrm{rpm}$ ) on biosurfactant production was studied. In order to evaluate cell growth and biosurfactant production, samples $(10 \mathrm{~mL})$ were taken at different time points during the fermentation. Cell concentration and surface tension were determined as described above. Whenever required, the culture broth supernatants were diluted 10 times with demineralized water, and the surface tension $\left(\mathrm{ST}^{-1}\right)$ was measured. All the experiments were performed in triplicate.

\subsection{Effect of environmental parameters on biosurfactant activity}

The effect of $\mathrm{pH}$, temperature and salinity on the activity of the biosurfactant produced by $W$. anomalus CCMA 0358 was studied using the cell-free supernatants obtained at the end of the fermentation conducted with the optimized culture medium in bioreactor, as described by Varjani and Upasani [4]. The effect of pH on surface activity was studied by adjusting the cell-free supernatants to different pH values $(2,4,6,8,10,12)$ using $1 \mathrm{~N} \mathrm{NaOH}$ or $1 \mathrm{~N} \mathrm{HCl}$ solutions, and measuring the surface tension as described above. To assess the effect of salinity on biosurfactant activity, the cell-free supernatants were supplemented with different $\mathrm{NaCl}$ concentrations $(50,100,200$ and $300 \mathrm{~g} / \mathrm{L})$; subsequently, the surface tension was measured as described above and compared with the values obtained without addition of $\mathrm{NaCl}$. The stability of the biosurfactant at high temperature was also determined; for that purpose, the cell-free supernatants were incubated at $121^{\circ} \mathrm{C}$ for $30 \mathrm{~min}$ and then allowed to cool to room temperature; the surface tension was measured and compared to the corresponding values before the heat treatment. All experiments were carried out in triplicate.

\subsection{Removal of crude oil from contaminated sand}

The potential applicability of the biosurfactant produced by $W$. anomalus CCMA 0358 in bioremediation was evaluated using artificially contaminated sand. Briefly, samples of $50 \mathrm{~g}$ of sand were mixed with $5 \mathrm{~g}$ of Arabian Light crude oil in $100 \mathrm{~mL}$ flasks and allowed to age at room temperature for $24 \mathrm{~h}$. Afterwards, $50 \mathrm{~mL}$ of cell-free supernatant (obtained at the end of the fermentation conducted in bioreactor with the optimized culture medium) were added to each flask. The flasks were incubated at $80 \mathrm{rpm}$ and $37^{\circ} \mathrm{C}$ for $24 \mathrm{~h}$. The oil removed was recovered from the surface and transferred to a graduated tube. In order to separate the water recovered together with the crude oil, the tubes were centrifuged $(2700 \times \mathrm{g}$, $20 \mathrm{~min}$ ), and subsequently the volume of crude oil was measured. The amount of crude oil recovered was calculated according to its density $(0.837 \mathrm{~g} / \mathrm{mL})$. Control assays were performed using demineralized water under similar conditions. All the experiments were carried out in triplicate.

\subsection{Statistical analysis}

The Statistica 8.0 software was used for all the statistical analysis. The mathematical model that relates the factors optimized in the CCD was determined through a second-order adjustment of the experimental data. All the determinations of surface tension and cell concentration were performed at least three times.

\section{Results and discussion}

\subsection{Optimization of biosurfactant production using response surface methodology (RSM)}

The yeast strain $W$. anomalus CCMA 0358 produced a new type of glycolipid biosurfactant using a culture medium containing yeast extract, ammonium sulfate, glucose and olive oil [27]. In this study, a RSM based on a CCD was used to optimize the concentration of the different medium components in order to maximize biosurfactant production by this yeast strain. Yeast extract $\left(X_{1}\right)$, ammonium sulfate $\left(X_{2}\right)$ and glucose $\left(X_{3}\right)$ were the independent factors selected to perform the optimization process. The corresponding levels for each factor are shown in Table 1. The design matrix (17 experiments) and the corresponding results of RSM experiments to determine the effect of the three abovementioned independent factors on the surface tension (response factor) are shown in Table 2 as observed and predicted values. Regression analysis of the optimization study indicated that yeast extract $\left(X_{1}\right)$ was the only significant factor $(p<0.1)$ on surface tension (Table 3$)$, whereas ammonium sulfate $\left(X_{2}\right)$ and glucose $\left(X_{3}\right)$ were found to be non-significant, as indicated by their high $p$ values (Table 3 ). Moreover, the interactions between the different medium components were found to be non-significant.

The results herein gathered were then fitted to a second-order polynomial equation that describes the surface tension (response 


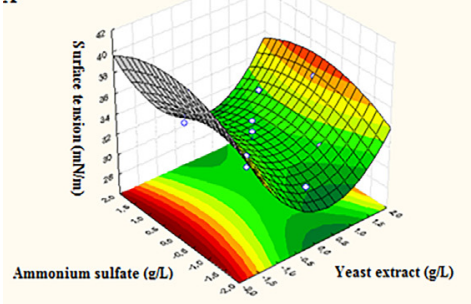

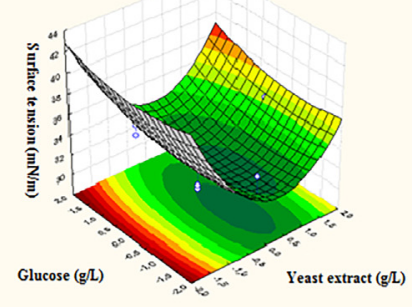

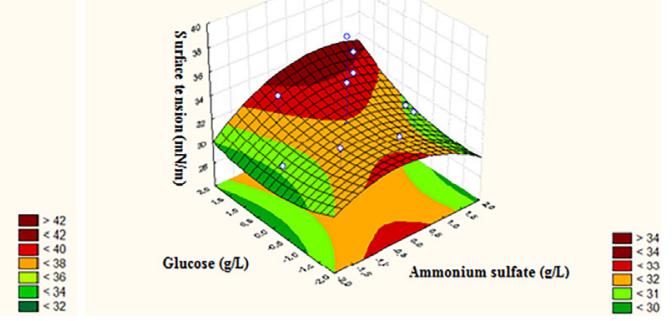

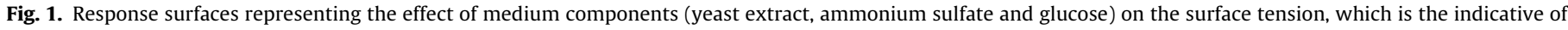
the production of biosurfactant. (A) Yeast extract $v$ s. ammonium sulfate; (B) Yeast extract vs. glucose; (C) Ammonium sulfate vs. glucose.

Table 3

Coefficient regression values for the model that describes the effects of the medium components in the surface tension.

\begin{tabular}{|c|c|c|c|c|}
\hline Factor & Terms & Regression coefficients & Standard error & $p$-value \\
\hline Yeast Extract $\left(X_{1}\right)$ & Linear & -1.1238 & 0.31865 & 0.009641 \\
\hline Ammonium sulfate $\left(X_{2}\right)$ & Linear & 0.2777 & 0.31865 & 0.412291 \\
\hline Glucose $\left(X_{3}\right)$ & Linear & 0.3446 & 0.31865 & 0.315358 \\
\hline$X_{1} X_{2}$ & Interactive & 0.0312 & 0.41616 & 0.942244 \\
\hline$X_{1} X_{3}$ & Interactive & 0.0812 & 0.41616 & 0.850755 \\
\hline$X_{2} X_{3}$ & Interactive & 0.2937 & 0.41616 & 0.503088 \\
\hline$X_{1}^{2}$ & Squared & 1.8169 & 0.35106 & 0.001287 \\
\hline$X_{2}^{2}$ & Squared & -0.4860 & 0.35106 & 0.208688 \\
\hline$X_{3}^{2}$ & Squared & 0.3288 & 0.35106 & 0.380125 \\
\hline
\end{tabular}

factor) based on the concentration of the significant medium components:

$Y=31.8106-1.1238 X_{1}+1.8169 X_{1}^{2}$

where $Y$ is the surface tension, and $X_{1}$ the concentration of yeast extract (the only component that was found to be significant). As ammonium sulfate and glucose were found to be non-significant, they were not included in the model equation. The regression equation obtained from ANOVA showed that $R^{2}$ (coefficient of determination) was 0.8792 , indicating that $87.9 \%$ of the variability in the responses could be explained by the second-order polynomial equation given above (Eq. (2)).

To establish the optimum level of each independent factor for maximum biosurfactant production, three-dimensional response surface plots were constructed by plotting the response (surface tension) as a function of two independent factors at a time, while maintaining the value of the other factor at its central level (Fig. 1). Finally, the optimum levels of yeast extract $\left(X_{1}=4.64 \mathrm{~g} / \mathrm{L}\right)$, ammonium sulfate $\left(X_{2}=4.22 \mathrm{~g} / \mathrm{L}\right)$ and glucose $\left(X_{3}=1.39 \mathrm{~g} / \mathrm{L}\right)$ that allow the highest biosurfactant production (i.e. the lowest surface tension value, estimated to be $31.5 \mathrm{mN} / \mathrm{m}$ ) can be obtained from the minimization of the previous equation.

In order to validate the optimum culture medium predicted by the model, $W$. anomalus CCMA 0358 was grown in flasks at the same conditions previously described, using a culture medium with the following composition: $4.64 \mathrm{~g} / \mathrm{L}$ yeast extract; $4.22 \mathrm{~g} / \mathrm{L}$ ammonium sulfate; $1.39 \mathrm{~g} / \mathrm{L}$ glucose; and $20 \mathrm{~g} / \mathrm{L}$ olive oil. The initial surface tension of this culture medium $(49.0 \pm 0.1 \mathrm{mN} / \mathrm{m})$ was reduced to $31.1 \pm 0.1 \mathrm{mN} / \mathrm{m}$ after $24 \mathrm{~h}$ of growth, which is very similar to the surface tension value predicted by the model $(31.5 \mathrm{mN} / \mathrm{m})$. Hence, it can be concluded that the model adequately adjusts the experimental data and clearly describes the effect of the culture medium composition on the biosurfactant production, as the experimental values obtained are in accordance with the expected values determined by the model.

Several authors reported the effect of yeast extract as nitrogen source (at concentrations between 1 and $10 \mathrm{~g} / \mathrm{L}$ ) for the production of biosurfactants by yeast strains belonging to the genera Candida, Pseudozyma and Pichia [18,19,28-31]. For instance, Konishi et al. [18] reported that growth and MEL production by Pseudozyma hubeiensis SY62 increased as the concentration of yeast extract increased from 1 to $10 \mathrm{~g} / \mathrm{L}$. However, yeast extract does not always have a positive effect on biosurfactant production. Daverey and Pakshirajan [17] reported that yeast extract at concentrations higher than $2 \mathrm{~g} / \mathrm{L}$ reduced the sophorolipid production by Starmerella bombicola NRRL Y-17069 (in this case, the highest sophorolipid production occurred under nitrogen-limiting conditions). It has also been reported that supplementing the culture medium with yeast extract at a concentration of $10 \mathrm{~g} / \mathrm{L}$ did not have any effect on the sophorolipid production by S. bombicola ATCC, 22214 [32].

In our previous assays, the different culture media were supplemented with olive oil at a concentration of $20 \mathrm{~g} / \mathrm{L}$. To further optimize the biosurfactant production by $W$. anomalus CCMA 0358, additional experiments were performed using the optimized culture medium supplemented with olive oil at different concentrations $(0-50 \mathrm{~g} / \mathrm{L})$. The assays were performed using the conditions previously described. The culture media supplemented with olive oil at concentrations between 10 and $50 \mathrm{~g} / \mathrm{L}$ led to similar surface tension values (around $31 \mathrm{mN} / \mathrm{m}$ ) after $24 \mathrm{~h}$ of growth (data not shown). For this reason, an olive oil concentration of $10 \mathrm{~g} / \mathrm{L}$ was selected to perform the following experiments to reduce the production costs of this biosurfactant.

Moreover, these results demonstrated that the presence of a hydrophobic carbon source (in this case olive oil) in the culture medium is essential for biosurfactant production by this yeast strain. The assays performed without olive oil led to surface tension values considerably higher $(40.6 \pm 0.1 \mathrm{mN} / \mathrm{m})$ when compared with those observed with the other culture media containing olive oil at different concentrations. The results herein obtained are in accordance with the general notion in the literature, as it has been widely reported that biosurfactant production by yeasts usually requires the simultaneous presence of a hydrophilic and a hydrophobic carbon source in the culture medium [17-19,21,28,29,32]. As an exception, Monteiro and co-workers [33] reported that the maximum glycolipid biosurfactant production by Trichosporon montevideense CLOA72 was achieved using sunflower oil $(20 \mathrm{~g} / \mathrm{L})$ as the sole carbon source. 
Table 4

Surface tension values ( $\mathrm{ST}$ and $\mathrm{ST}^{-1}, \mathrm{mN} / \mathrm{m}$ ) and cell concentrations (cells/mL) obtained with Wickerhamomyces anomalus CCMA 0358 grown in bioreactor using the optimized culture medium at different agitation speeds $(250-500 \mathrm{rpm})$. ST: surface tension of the cell-free supernatant; $\mathrm{ST}^{-1}$ : surface tension of the cell-free supernatant diluted 10 times with demineralized water. The results presented correspond to the values obtained at the optimum time for each condition ( $24 \mathrm{~h}$ ). Results represent the average of three independent experiments \pm standard deviation.

\begin{tabular}{llll}
\hline Agitation speed $(\mathrm{rpm})$ & $\mathrm{ST}(\mathrm{mN} / \mathrm{m})$ & $\mathrm{ST}^{-1}(\mathrm{mN} / \mathrm{m})$ & Growth $\left(\right.$ cells $\left.\times 10^{8} / \mathrm{mL}\right)$ \\
\hline 250 & $34.5 \pm 1.0$ & $42.2 \pm 0.7$ & $4.7 \pm 0.1$ \\
300 & $32.8 \pm 0.5$ & $39.9 \pm 0.3$ & $4.5 \pm 0.2$ \\
350 & $31.2 \pm 0.4$ & $38.0 \pm 0.9$ & $2.7 \pm 0.2$ \\
400 & $31.0 \pm 0.2$ & $38.4 \pm 0.3$ & $2.0 \pm 0.1$ \\
500 & $29.3 \pm 0.4$ & $33.9 \pm 0.1$ & $2.0 \pm 0.2$ \\
\hline
\end{tabular}

Furthermore, it has to be pointed out that the concentration of the hydrophobic carbon source used in this study was considerably lower when compared with other works, where oleic acid, cotton seed oil, olive oil, coconut oil or soybean oil at concentrations between 75 and $150 \mathrm{~g} / \mathrm{L}$ were added to the culture medium [17-19,28,32].

\subsection{Biosurfactant production in bioreactor}

Growth and biosurfactant production by W. anomalus CCMA 0358 were evaluated in a 5-L bioreactor aiming at an increase of the production scale. The culture medium used in these assays was that optimized previously in flasks, and the effect of the agitation speed (250-500 rpm) on biosurfactant production (assessed as the reduction of the surface tension of the culture medium) was evaluated. In all cases, air was injected into the culture medium at a constant flow rate of $1 \mathrm{~L} / \mathrm{min}(0.5 \mathrm{vvm}$ (volume of air per culture volume and minute)). The results obtained (Table 4) indicated that a higher agitation speed resulted in a lower surface tension value at the end of the fermentation. The initial surface tension of the culture medium was $49.1 \pm 0.1 \mathrm{mN} / \mathrm{m}$, and the lowest surface tension value $(29.3 \pm 0.4 \mathrm{mN} / \mathrm{m})$ was achieved in fermentations performed at $500 \mathrm{rpm}$, after $24 \mathrm{~h}$ of growth. However, as it can be seen from Table 4, an increase in the agitation speed led to a decrease in the number of cells at the end of the fermentation.

Other authors earlier reported results similar to those obtained in this study whereby a high agitation speed is more favorable for biosurfactant production by different yeast strains; agitation rates between 350 and $550 \mathrm{rpm}$ have been commonly used for biosurfactant production by different yeasts in bioreactor, with air-flow rates between 1 and $2 \mathrm{vvm}[17,19,21]$. Contrarily, the optimum conditions for biosurfactant production by Candida lipolytica UCP0988 in bioreactor were a low agitation rate $(200 \mathrm{rpm})$ without air injection [23].

One parameter that contributes to the production costs of biosurfactants is the fermentation time. In the case of $W$. anomalus CCMA 0358, the lowest surface tension value (i.e. the highest biosurfactant production) was achieved after $24 \mathrm{~h}$ of growth. However, in most of the yeast strains reported in the literature, longer incubation times (usually $144-240 \mathrm{~h}$ ) are required to achieve the maximum biosurfactant production $[17,19,21,23]$. This represents an important advantage of $W$. anomalus CCMA 0358 over other commonly used yeasts.

Fig. 2 shows the evolution of growth and surface tension for the fermentation performed in bioreactor at $500 \mathrm{rpm}$. As it can be seen, up to $14 \mathrm{~h}$ of fermentation there is an inverse relationship between both parameters, indicating a growth-associated biosurfactant production. After that point, the number of cells decreased, whereas the surface tension remained constant up to $24 \mathrm{~h}$. Afterwards, a slight increase in the surface tension was observed, probably due to a partial degradation of the biosurfactant. On the contrary, the
Table 5

Effect of $\mathrm{pH}$ and $\mathrm{NaCl}$ concentration on surface activity. Surface tension values (ST, $\mathrm{mN} / \mathrm{m}$ ) obtained with the cell-free supernatants from Wickerhamomyces anomalus CCMA 0358 (grown in bioreactor using the optimized culture medium) supplemented with different $\mathrm{NaCl}$ concentrations and at different $\mathrm{pH}$ values. The surface tension values were determined at room temperature $\left(25^{\circ} \mathrm{C}\right)$. Results represent the average of three independent experiments \pm standard deviation.

\begin{tabular}{lll}
\hline & & $\mathrm{ST}(\mathrm{mN} / \mathrm{m})$ \\
\hline$[\mathrm{NaCl}](\mathrm{g} / \mathrm{L})$ & 0 & $29.3 \pm 0.4$ \\
& 50 & $28.2 \pm 0.5$ \\
& 100 & $28.9 \pm 0.1$ \\
& 200 & $29.2 \pm 0.3$ \\
$\mathrm{pH}$ & 300 & $29.1 \pm 0.2$ \\
& 2 & $34.7 \pm 0.9$ \\
& 4 & $33.9 \pm 0.7$ \\
& 6 & $31.5 \pm 0.8$ \\
& 8 & $30.7 \pm 0.3$ \\
& 10 & $31.5 \pm 0.6$ \\
& 12 & $30.5 \pm 0.6$ \\
\hline
\end{tabular}

production of sophorolipids by several yeast strains occurs mainly during the stationary growth phase [21,32]. However, Monteiro and co-workers [33] reported a partially growth-associated biosurfactant production by T. montevideense CLOA72 (70\% of the biosurfactant was produced during the exponential growth phase).

The great advantage of the present study when compared with others previously reported is the faster $(24 \mathrm{~h})$ biosurfactant production achieved with $W$. anomalus CCMA 0358.

\subsection{Effect of temperature, $\mathrm{pH}$ and salinity on biosurfactant activity}

The applicability of biosurfactants can be conditioned by the effect of $\mathrm{pH}$, temperature and salinity on their stability and performance. For instance, the stability of biosurfactants at high temperature is of great importance for their use in the food and oil industries, as well as for their incorporation in laundry detergents [25]. The biosurfactant produced by $W$. anomalus CCMA 0358 was found to be stable at high temperature. The surface tension of the cell-free supernatant remained constant (around $29 \mathrm{mN} / \mathrm{m}$ ) after incubation at $121^{\circ} \mathrm{C}$ for $20 \mathrm{~min}$, indicating no loss of activity. In a similar way, other biosurfactants produced by yeasts were not affected by incubations at high temperatures $\left(80-120^{\circ} \mathrm{C}\right)$ [17,22,28,29,33].

Regarding the effect of salinity, $\mathrm{NaCl}$ concentrations as high as $300 \mathrm{~g} / \mathrm{L}$ did not have a negative effect on biosurfactant activity, as it can be seen from the surface tension values obtained (Table 5). The lowest surface tension value $(28.2 \pm 0.5 \mathrm{mN} / \mathrm{m})$ was obtained for a $\mathrm{NaCl}$ concentration of $50 \mathrm{~g} / \mathrm{L}$. This property makes this biosurfactant useful for applications involving high salinities, such as bioremediation of marine environments. Other biosurfactants produced by yeasts have been reported to remain stable at $\mathrm{NaCl}$ concentrations up to $100 \mathrm{~g} / \mathrm{L}$ [28], $120 \mathrm{~g} / \mathrm{L}$ [22], $150 \mathrm{~g} / \mathrm{L}$ [29], $200 \mathrm{~g} / \mathrm{L}$ [17] and $300 \mathrm{~g} / \mathrm{L}$ [33].

Regarding the effect of $\mathrm{pH}$, the biosurfactant produced by $W$. anomalus CCMA 0358 was more stable under neutral and alkaline conditions ( $\mathrm{pH}$ 6-12), where the surface tension remained almost constant (Table 5). On the contrary, at acidic $\mathrm{pH}$ values, a slight increase in the surface tension values was observed, meaning that the biosurfactant was less active in those conditions. The stability of this biosurfactant at $\mathrm{pH}$ values between 6 and 12 is useful for its application in laundry detergent formulations, which $\mathrm{pH}$ is usually in the range of 9-12 [25]. Other biosurfactants produced by yeasts remained stable at $\mathrm{pH}$ values between 2 and 12 [28,29]. In other cases, a partial loss of activity was observed at high $\mathrm{pH}$ values $(\mathrm{pH}$ 12) [17,33], whereas other biosurfactants remained stable only at $\mathrm{pH}$ values between 6 and 10 [22]. 


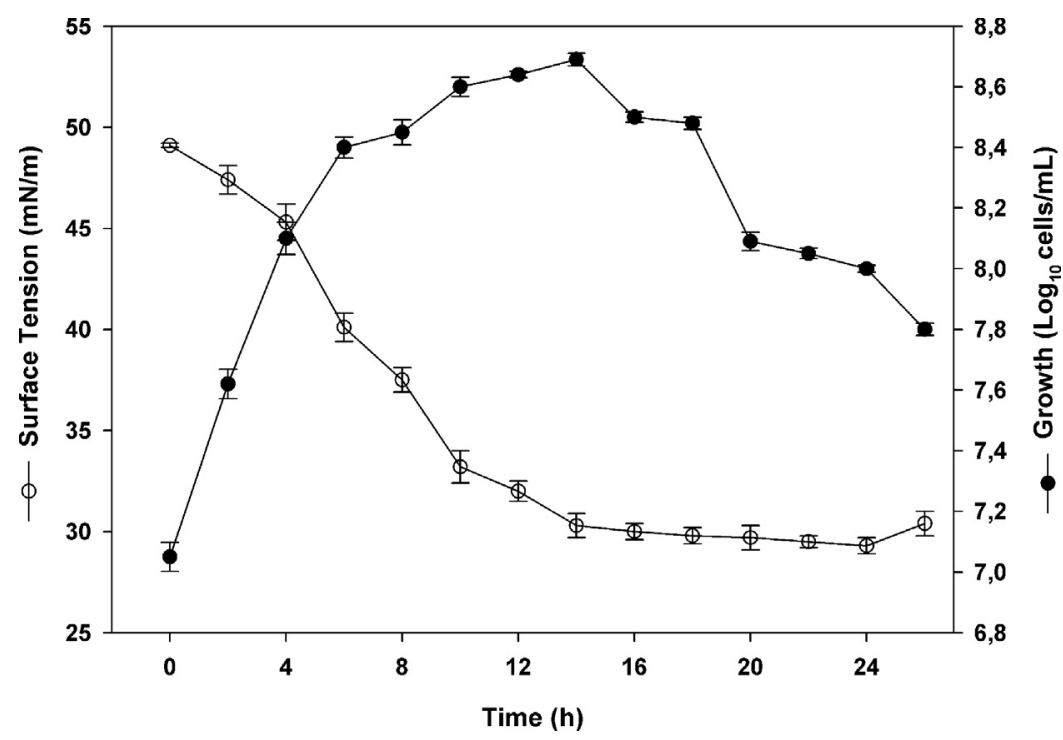

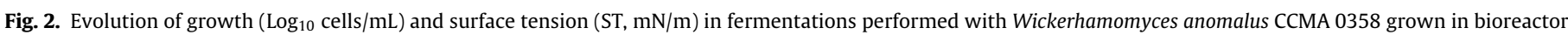
using the optimized culture medium at $28^{\circ} \mathrm{C}$ and $500 \mathrm{rpm}$. Results represent the average of three independent experiments \pm standard deviation.

\subsection{Bioremediation assays}

The biosurfactant produced by $W$. anomalus CCMA 0358 was evaluated for its ability to remove crude oil from artificially contaminated sand. The cell-free supernatant obtained at the end of the fermentation performed using the optimized culture medium allowed the recovery of about $20 \pm 4 \%$ of the oil impregnated in the sand when compared with the control assays (performed with demineralized water at the same conditions). One advantage of biosurfactants for application in bioremediation is their possible use without purification (i.e. as cell-free supernatants), which contributes to increase their competitiveness with chemical surfactants, as the purification steps can account for up to $60-70 \%$ of their total production costs [3,9].

The potential use of biosurfactants produced by several yeasts in bioremediation has been reported by other authors. The biosurfactants produced by C. lipolytica UCP0988 and Candida glabrata UCP1002 were found to remove between $19 \%$ and $43 \%$ (depending on the biosurfactant concentration and the sand particle size) of motor oil from contaminated sand when compared with a control performed with demineralized water $[22,28]$. Moreover, sophorolipid biosurfactants produced by S. bombicola ATCC 22214 recovered up to $27 \%$ of crude oil in core-flooding experiments [29]. The results herein obtained were similar to those reported for the lipopeptide biosurfactant surfactin produced by Bacillus subtilis \#573, which led to recoveries between 19 and 26\% (depending on the culture medium used to grow the microorganism) of crude oil from contaminated sand in similar assays $[13,20]$.

These results, together with the stability of this biosurfactant at high temperature, as well as over a wide range of salinities and $\mathrm{pH}$ values, make it a promising candidate for application in bioremediation processes.

\section{Conclusions}

The biosurfactant produced by $W$. anomalus CCMA 0358 exhibited excellent surface active properties, as demonstrated by the low surface tension values achieved (from $49 \mathrm{mN} / \mathrm{m}$ up to $29 \mathrm{mN} / \mathrm{m}$ ). Furthermore, it remained stable at high temperature $\left(121^{\circ} \mathrm{C}\right)$, high salinities $(300 \mathrm{~g} / \mathrm{L} \mathrm{NaCl})$ and $\mathrm{pH}$ values between 6 and 12 . The crude biosurfactant allowed the recovery of $20 \%$ of crude oil from contaminated sand. The excellent surface tension reducing ability exhibited by this biosurfactant, together with its stability under extreme environmental conditions, as well as its ability to recover crude oil from contaminated sand make it a promising candidate for application in bioremediation or in the petroleum industry, as an alternative to the traditional chemical surfactants.

\section{Conflicts of interest}

None.

\section{Acknowledgements}

The authors acknowledge the Portuguese Foundation for Science and Technology (FCT) for the financial support under the scope of the strategic funding of UID/BIO/04469/2013 unit and COMPETE 2020 (POCI-01-0145-FEDER-006684), and BioTecNorte operation (NORTE-01-0145-FEDER-000004) funded by the European Regional Development Fund under the scope of Norte2020 - Programa Operacional Regional do Norte. The authors also thank the FCT for the financial support under the scope of the Project MultiBiorefinery - Multi-purpose strategies for broadband agro-forest and fisheries by-products valorisation: a step forward for a truly integrated biorefinery (POCI-01-0145-FEDER-016403). E. J. Gudiña was supported by the Post-Doctoral grant CEBBPD/01/2015/07 from the project UID/BIO/04469/2013, funded by FCT.

\section{References}

[1] D.W.G. Develter, L.M.L. Lauryssen, Properties and industrial applications of sophorolipids, Eur. J. Lipid Sci. Technol 112 (2010) 628-638.

[2] I.N.A. Van Bogaert, J. Zhang, W. Soetaert, Microbial synthesis of sophorolipids, Process. Biochem. 46 (2011) 821-833.

[3] I.M. Banat, S.K. Satpute, S.S. Cameotra, R. Patil, N.V. Nyayanit, Cost effective technologies and renewable substrates for biosurfactants' production, Front. Microbiol. 5 (2014) 697.

[4] S.J. Varjani, V.N. Upasani, Core flood study for enhanced oil recovery through ex-situ bioaugmentation with thermo- and halo-tolerant rhamnolipid produced by Pseudomonas aeruginosa NCIM 5514, Bioresour. Technol. 220 (2016) 175-182.

[5] F. Zhao, J.D. Zhou, F. Ma, R.J. Shi, S.Q. Han, J. Zhang, Y. Zhang, Simultaneous inhibition of sulfate-reducing bacteria, removal of $\mathrm{H}_{2} \mathrm{~S}$ and production of rhamnolipid by recombinant Pseudomonas stutzeri Rhl: applications for microbial enhanced oil recovery, Bioresour. Technol. 207 (2016) 24-30. 
[6] L.M. Whang, P.W. Liu, C.C. Ma, S.S. Cheng, Application of biosurfactants, rhamnolipid, and surfactin, for enhanced biodegradation of diesel-contaminated water and soil, J. Hazard. Mater. 151 (2008) 155-163.

[7] S.J. Varjani, Microbial degradation of petroleum hydrocarbons, Bioresour. Technol. 223 (2017) 277-286.

[8] R. Marchant, I.M. Banat, Biosurfactants: a sustainable replacement for chemical surfactants? Biotechnol. Lett. 34 (2012) 1597-1605.

[9] S.J. Varjani, V.N. Upasani, Critical review on biosurfactant analysis, purification and characterization using rhamnolipid as a model biosurfactant, Bioresour. Technol. 232 (2017) 389-397.

[10] D.W.F. Oliveira, A. Burgos, M. Lechuga Villena, M. García Román, V.V.M. Melo L.R.B. Gonçalves, D.A. Vaz, Aquatic toxicity and biodegradability of surfactant produced by Bacillus subtilis ICA56, J. Environ. Sci. Health, Part A 52 (2017) 174-181.

[11] S. Claus, I.N.A. Van Bogaert, Sophorolipid production by yeasts: a critical review of the literature and suggestions for future research, Appl. Microbiol. Biotechnol. 101 (2017) 7811-7821.

[12] Grand View, Research, Biosurfactants Market by Product (Rhamnolipids, Sophorolipids, MES, APG, Sorbitan Esters, Sucrose Esters) Expected to Reach USD 2308.8 Million by 2020, 2014 (Accessed 25 July 2014) http://www. grandviewresearch.com/industryanalysis/biosurfactants-industry.

[13] J.F.B. Pereira, E.J. Gudiña, R. Costa, R. Vitorino, J.A. Teixeira, J.A.P. Coutinho, L.R. Rodrigues, Optimization and characterization of biosurfactant production by Bacillus subtilis isolates towards microbial enhanced oil recovery applications, Fuel 111 (2013) 259-268.

[14] J.M. Luna, R.D. Rufino, L.A. Sarubbo, L.R. Rodrigues, J.A. Teixeira, G.M. Campos-Takaki, Evaluation antimicrobial and antiadhesive properties of the biosurfactant lunasan produced by Candida sphaerica UCP 0995, Curr. Micorbiol. 62 (2011) 1527-1534.

[15] A.J. Cortés-Sánchez, H. Hernández-Sánchez, M.E. Jaramillo-Flores, Biological activity of glycolipids produced by microorganisms: new trends and possible therapeutic alternatives, Microbiol. Res. 168 (2013) 22-32.

[16] T. Morita, M. Konishi, T. Fukuoka, T. Imura, H.K. Kitamoto, D. Kitamoto, Characterization of the genus Pseudozyma by the formation of glycolipid biosurfactants, mannosylerythritol lipids, FEMS Yeast Res. 7 (2007) 286-292.

[17] A. Daverey, K. Pakshirajan, Sophorolipids from Candida bombicola using mixed hydrophilic substrates: production, purification and characterization, Colloids Surf. B Biointerfaces 79 (2010) 246-253.

[18] M. Konishi, T. Nagahama, T. Fukuoka, T. Morita, T. Imura, D. Kitamoto, Y. Hatada, Yeast extract stimulates production of glycolipid biosurfactants, mannosylerythritol lipids, by Pseudozyma hubeiensis SY62, J. Biosci. Bioeng. 111 (2011) 702-705.

[19] V.K. Morya, J. Park, T.J. Kim, S. Jeon, E.K. Kim, Production and characterization of low molecular weight sophorolipid under fed-batch culture, Bioresour. Technol. 143 (2013) 282-288.
[20] E.J. Gudiña, E.C. Fernandes, A.I. Rodrigues, J.A. Teixeira, L.R. Rodrigues, Biosurfactant production by Bacillus subtilis using corn step liquor as culture medium, Front. Microbiol. 6 (2015) 59.

[21] G.L. Maddikeri, P.R. Gogate, A.B. Pandit, Improved synthesis of sophorolipids from waste cooking oil using fed batch approach in the presence of ultrasound, Chem. Eng. J. 263 (2015) 479-487.

[22] D.K.F. Santos, R.D. Rufino, J.M. Luna, V.A. Santos, A.A. Salgueiro, L.A. Sarubbo, Synthesis and evaluation of biosurfactant produced by Candida lipolytica using animal fat and corn steep liquor, J. Petrol. Sci. Eng. 105 (2013) 43-50.

[23] D.K.F. Santos, Y.B. Brandão, R.D. Rufino, J.M. Luna, A.A. Salgueiro, V.A. Santos, L.A. Sarubbo, Optimization of cultural conditions for biosurfactant production from Candida lipolytica, Biocatal. Agric. Biotechnol. 3 (2014) 48-57.

[24] J. Coronel-León, A.M. Marqués, J. Bastida, A. Manresa, Optimizing the production of the biosurfactant lichenysin and its application in biofilm control, J. Appl. Microbiol. 120 (2015) 99-111.

[25] K. Bhange, V. Chaturvedi, R. Bhatt, Simultaneous production of detergent stable keratinolytic protease, amylase and biosurfactant by Bacillus subtilis PF1 using agro industrial waste, Biotechnol. Rep. 10 (2016) 94-104.

[26] S.J. Varjani, V.N. Upasani, Carbon spectrum utilization by an indigenous strain of Pseudomonas aeruginosa NCIM 5514: production, characterization and surface active properties of biosurfactant, Bioresour. Technol. 221 (2016) $510-516$.

[27] K.S.T. Souza, E.J. Gudiña, Z. Azevedo, V. de Freitas, R.F. Schwan, L.R. Rodrigues, D.R. Dias, J.A. Teixeira, New glycolipid biosurfactants produced by the yeast strain Wickerhamomyces anomalus CCMA 0358, Colloids Surf. B Biointerfaces 154 (2017) 373-382.

[28] J.M. Luna, L. Sarubbo, G.M. Campos-Takaki, A new biosurfactant produced by Candida glabrata UCP 1002: characteristics of stability and application in oil recovery, Braz. Arch. Biol. Technol. 52 (2009) 785-793.

[29] A.E. Elshafie, S.J. Joshi, Y.M. Al-Wahaibi, A.S. Al-Bemani, S.N. Al-Bahry, D Al-Maqbali, I.M. Banat, Sophorolipids production by Candida bombicola ATCC 22214 and its potential application in microbial enhanced oil recovery, Front. Microbiol. 6 (2015) 1324.

[30] J. Thaniyavarn, T. Chianguthai, P. Sangvanich, N. Roongsawang, K. Washio, M. Morikawa, S. Thaniyavarn, Production of sophorolipid biosurfactant by Pichia anomala, Biosci. Biotechnol. Biochem. 72 (2008) 2061-2068.

[31] E. Dzięgielewska, M. Adamczak, Evaluation of waste products in the synthesis of surfactants by yeasts, Chem. Pap. 67 (2013) 1113-1122.

[32] A. Samad, J. Zhang, D. Chen, Y. Liang, Sophorolipid production from biomass hydrolysates, Appl. Biochem. Biotechnol. 175 (2015) 2246-2257.

[33] A.S. Monteiro, J.O.P.A. Coutinho, C. Ary, C.A. Rosa, E.P. Siqueira, V.L. Santos, Characterization of new biosurfactant produced by Trychosporon montevidense CLOA72 isolated from dairy industry effluents, J. Basic Microbiol. 49 (2009) 1-11. 